\title{
Port performance: The importance of land transport in a developing economy
}

\author{
Mobolaji S. Stephens ${ }^{1}$ and Wilfred I. Ukpere ${ }^{2 \star}$ \\ ${ }^{1}$ Department of Transport Management Technology, Federal University of Technology, Owerri, Imo State, Nigeria. \\ ${ }^{2}$ Department of Industrial Psychology and People Management, Faculty of Management, University of Johannesburg, \\ South Africa.
}

Accepted 12 July, 2011

\begin{abstract}
This study set out to establish that land transport system in the country of destination, determines the turn-around time, capacity utilisation of port infrastructure, facilities and cargo-handling equipment and general port performance. Of particular interest, is the contribution of road transport infrastructures and system to the magnitude of turn-around time, port performance and general economic growth and development. This is true and significant for developing countries of Sub-Saharan Africa, where transport systems are poorly developed and sparsely integrated; but the economies are import oriented. The port's rates of capacity utilisation was determined over a period 14 years (1990 to 2007) and a study of ship traffic was done for 156 vessels calling at the port and 19, 296 loaded road vehicles leaving the port between 1 December, 2006 and 31 March, 2007. The result showed that over-utilisation of road transport resulted in under-utilisation of several port infrastructures, port congestion; longer turn-around time and general poor performance of the port. The need for a well-integrated transport system was therefore underlined.
\end{abstract}

Key words: Capacity utilisation, turn-around time, berth effectiveness.

\section{INTRODUCTION}

The primary function of a seaport is to transfer cargo between maritime and inland transport, quickly, efficiently and at a reasonable cost. For this to happen, it means the available capacities in terms of berths space, cargo handling equipment and cargo throughout must be utilized effectively. In order to appreciate the first statement fully, one has to examine the influence of ports and their performance in international seaborne trade. According to the report of United Nations Conference on Trade and Development/Swedish International Development Authority (UNCTAD/SIDA), 1983, the major costs of maritime transport relate to cargo handling costs at the ports. Ports are therefore important to all domestic and international economics. Every nation relies on its transportation systems for the movement of the people and goods within as well as outside its geographical territory, a part of which ports are (ICC, 1992, 1993).

\footnotetext{
*Corresponding author. E-mail: wilfredukpere@gmail.com
}

Transport costs are an extremely important component of distribution costs. And distribution costs are the bulk of cost prices of most (if not all) commodities. Transport cost includes inland transport (between the place of production and the port of shipment, from the port of import to the consignee) and maritime transport (the cost of handling the goods through the ports of export and import and the cost of carrying the goods on the "sea leg" freights) (Pieter, 1998). These maritime costs form the major part of the over-all transport cost and from largely part of the overall cost of the cargo. Hence, reducing cargo-handling cost will have a great impact in reducing cost of commodities, improving world economies and standard of living of the people of the world. Reducing cargo-handling cost invariably means improving ports performance and utilizing optimally, their capacities (Briggs, 1989). This makes the study of ports capacity utilization and performance very important to every state or government intent on improving her citizens' standard of living (Figure 1).

However, worthy of note is the fact that the 


\section{EXPORT PRODUCT COST}
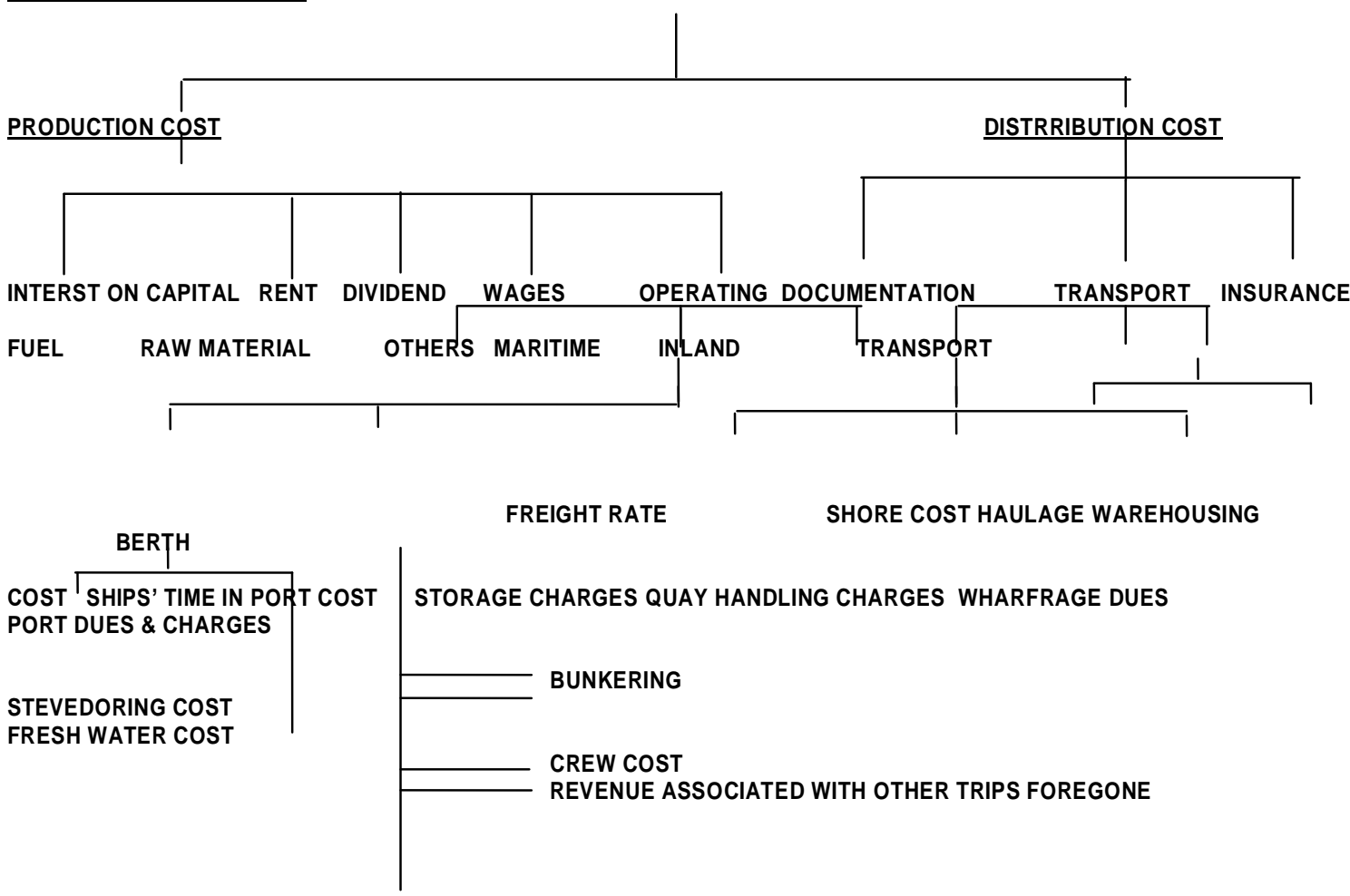

Figure 1. Export product cost distribution.

performance of a port is dependent not only on the port activities and how well it has managed them, but also on the availability of land transport systems and how well they are organised and maintained to meet the demand placed on them (Pyre, 1989). Poor performance of the land transport system or their unavailability can in turn lead to poor performance for the seaports in the country in question.

\section{Objective of the study}

The main objective of the study is to determine the causes of the congestion at the seaport given the fact that the port performance indicators showed that the port is doing well. In addition to this, the following are subobjectives:

i. Determine the port connectivity to its hinterland and the capacity utilization of the land infrastructures.

ii. Develop a ship traffic queue and a road vehicle traffic queue for vessels and road vehicles calling at the port.

iii. Determine the port infrastructural and cargo handling capacity utilization.

\section{Research questions}

The following questions will have to be answered in order to attain our objectives: i. What are the land modal connections to the seaport?

ii. What are the degrees of utilization of the land transport infrastructures to the seaport?

iii. What are the queue systems in the seaport?

iv. What is the capacity utilization of the port facilities for cargo handling purposes?

v. What are the port berth occupancy and the port turnaround time?

\section{Theory of the study}

The economics importance $(E)$ of a given port $(J)$ is directly proportional to the amount of inward and outward traffic (a) in the ports hinterland, minus the cargo (F) that could pass through the port, but which is attracted to another port (Emeghara, 1992):

$E_{j} \alpha a_{j}-f$

$\mathrm{E}_{\mathrm{j}}=\mathrm{K}\left(a_{j}-f\right)$

Also, this volume of cargo passing through the port (j) is directly proportional to the number of vessels calling (i) at the port and inversely proportional to the turn-round time (I) at the port.

$a_{\mathrm{j}} \alpha \mathrm{i} / \mathrm{l}$ :

$a_{j}=g i / l$ 
Again, the turn-round time $(I)$ at the port is inversely proportional to the extent of the efficiency of the land transport $(t)$, of other instrument factors such as the government policies and financial practice $(u)$ :

la $1 /(t+u)$

$I=q /(t+u)$

From afore equation, it can be deduced that capacity of the port in terms of number of berths and cargo handling capabilities as well as demand for such facilities in terms of vessel call and cargo throughput determine the importance of a port.

However, using probability distribution, the probability of no vessel at the port $\left(P_{0}\right)$ is given by:

$P o=c !(1-P) /(p c) C+c !(1-p) c-1$

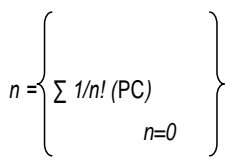

Where $\mathrm{c}=$ number of channels/berth, $\mathrm{n} !=$ Factorial $p=$ traffic intensity, $n=$ integers from 0 to $(\mathrm{c}-\mathrm{I})$

\section{LITERATURE REVIEW}

Bird (1970) defined a seaport in terms of its function as a place where exchange of goods and passengers between land and sea transport regularly occur. "It is a known fact that some heavy and voluminous goods move across international boarders move cheaply and efficiently by sea than by any other mode of transport" (Immer, 1984). Langon (1998) picked time as the most important factor in measuring the efficiency of any transport system. Levinson (1988) said it is an economic waste when facilities (capacities) lie idle, as funds used in providing them could be used to provide other goods and services for the people. Therefore, the port capacity, utilization as well as time spent in the port are very important.

The port is a sub-system in the overall transport system (Pieter, 1998). The transport system equally forms a part of the socio-economic system of our society and the international trade. This concept of port as a system was first adopted in the study of ports of Los Angeles and San Francisco (Thomas and Roach, 1984). They observed that this methodology applies analytical techniques to determining port productivity and bringing into focus, the complex interactions experienced at the land and sea interference: potentials for substantial improvements in performance and reduction in costs. United Nations Conference on Trade and Developments (UNCTAD) Work to Port System, a manual on port management referred to the following as sub-systems in a port system: the hold system (ship); hook system (ship); quay transfer system, storage system, shed delivery system, inland waterways/canal system, railway system and road system.
The efficiency of the sub-systems in relation to each other, Okafor (1998) said it is very important in the efficient operation of the entire port system. He described it as a system of links and nodes with established actual capacities and range of cycles (operation times). The inefficient working of a sub-system could ultimately affect that of the whole economy assuming only such port serves the whole country.

Wolfhard (1989) note under-utilisation of capacity as one of the major problems of ports in developing countries. According to Laing and Hecker (1989), the main justification for port investment is the reduction of ship's waiting time in over-crowded ports. In calculating waiting time, they (Laing and Hecker) used estimates of berth occupancy from traffic and productivity forecasts to determine waiting-to-service time ratio $(\mathrm{w} / \mathrm{s})$ of a port. They suggested that $\mathrm{w} / \mathrm{s}$ could be calculated directly from queuing theory or from tables based on queuing theory or by simulation if queuing theory is not applicable.

\section{METHODOLOGY}

Road traffic within the port, particularly at the exit points was observed with the assistance of field research workers - covering the three exit and the emergency lanes. They recorded the service start times and end of service times for all out-going loaded road vehicles (Mondays through Fridays between 1100 and 1700 hours) for four (4) months. A total of nineteen thousand two hundred and ninety-six $(19,296)$ such vehicles were recorded. The researcher during this period recorded the arrival time for each of the road vehicles.

Ship traffic for vessels calling at the port during the same period was recorded daily from ship traffic data report, quay record book and ship's record folder, all raw data. The extracts collected were arrival times, berthing times, service start times, ship/berth idle times, end of service times, ship departure times, berth worked/ used, ship length, cargo throughput and berth effectiveness. A total of one hundred and fifty-six (156) vessels were observed.

For road traffic queue study, out-going traffic was examined because most of the cargo dispatched from the port were taken away by road and conditions of roads outside the port can not be controlled or affected directly by decisions taken within the port either by the port operators or the shippers and their agents. Apart from this, points of destination vary for different cargo and consignees The queue study were done manually and covered the followings: ship arrivals and berth allocations (noting the times); berth and quayside operations (including cargo discharge methods, volumes and times, noting delays); mode of conveyance of cargo out of port; arrival time and service time at exit points for road vehicles. Poisson distribution was used. This model was developed using Hay (1978) study as a reference point.

Port performance indicators (PPI) were used to determine the port performance levels. Databases of LPC were accessed to provide information for the PPI and for the study of on capacity utilisation of storage facilities (sheds, warehouses and stacking areas), rail and road, pipeline and suction pump infrastructures.

\section{RESULTS AND DISCUSSION}

\section{Queues}

The study of the road traffic showed that, an arrival rate 


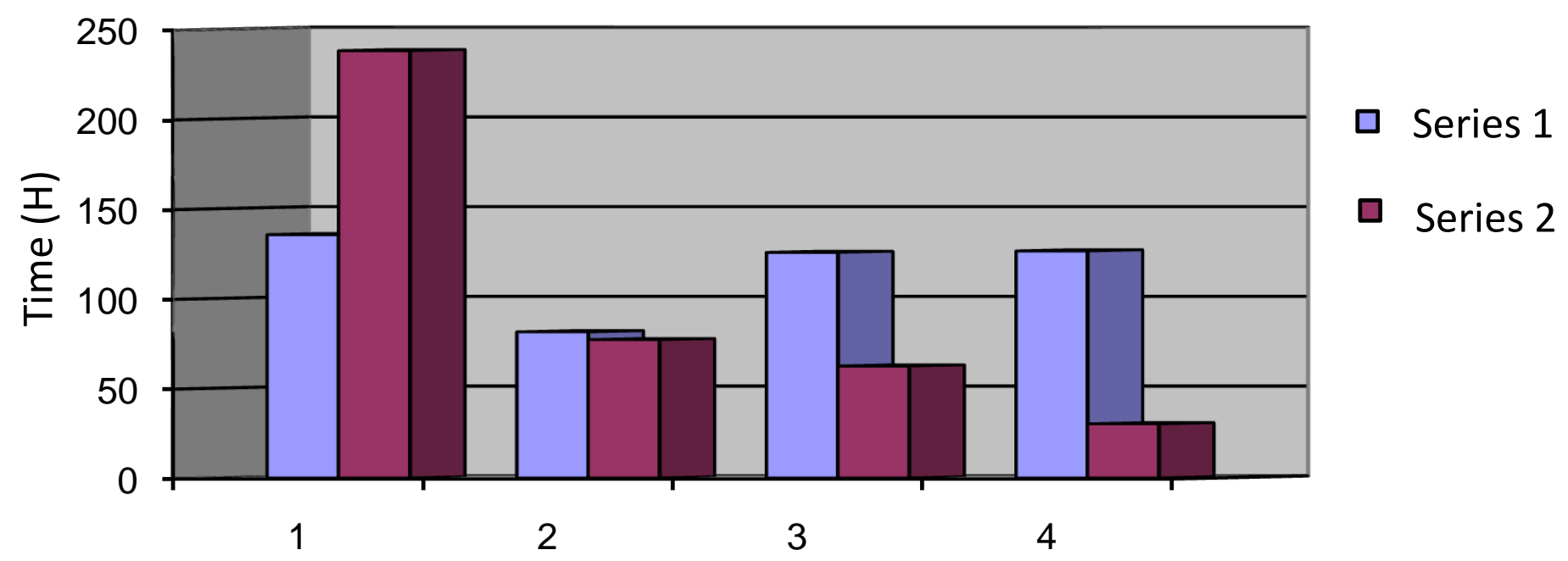

\section{Months of study (Dec 2007, Jan 2008, Feb 2008 and Mar 2008)}

Figure 2. Comparing berth working time and berth idle time for ship at port; series 1: berth working time, series 2: berth idle time (Source: field work).

of 0.66 vehicles per minutes was recorded with the service rate being 0.18 vehicles per minute. Each vehicle waited for at least 10.42 min to be served. A very high traffic intensity of 0.92 was recorded. The probability of no road vehicle leaving the port is 0.008675 . The average time such a vehicle spent leaving the port from the point it joined the queue is $7 \mathrm{~min}$. While the average time a road vehicle spends in the queue is just 1.062 min. A careful look at the total time spent leaving the port, that is, $7 \mathrm{~min}$, and time spent in the queue is just 1.062 min shows that unnecessary time is been wasted at the gates as the vehicles are being served. More time is therefore wasted at the gates than on the queue. At any point in time, about 13 road vehicles are leaving the port, that is, at the gate area. While at least, 10 road vehicles will always be on the queue leaving the port. The probability of queuing on arrival at the gates is 0.828627 . This is rather high and suggests a considerable degree of congestion.

On the other hand, the ship traffic study showed arrival and service rates of 1.36 and 0.118 ships per day respectively. Arriving vessels wait on the average for 3.2 $\mathrm{h}$ to be berthed. A traffic intensity of 0.48 was recorded, meaning that vessels traffic is low. This contradicts the high level of cargo congestion at port. The probability of no vessel at the port is 0.0000167 . Average time a vessel spent at the port (that is, queuing and service time) is 7.353 days. Average time spent in queue (including time there is no queue) by ship is $0.04 \mathrm{~h}$. Average number of ships in the system (that is, at the port at any point in time) is 11 ships. It means that at any time, only $50 \%$ of the berth capacity is being used, as there are 22 berths at the port. Average number of vessels in the queue is 0.0048378 , while the probability of not queuing on arrival at the port is 0.998 .
From this queue study, it is obvious that the use of direct cargo discharge method unto waiting road traffic led to a longer time in port of 7.4 days. This was due to berth idle time that resulted from time loss while waiting for road vehicles to return for re-loading at the berths. This is well illustrated in Figure 2 where berth-working time was compared with berth idle time was shown on monthly basis.

\section{Methods of cargo discharge}

Majority of the port users prefer to take delivery of their goods from the port using direct delivery method. Here, as soon as the consignments are being discharged from the vessel, they are loaded unto series of road vehicles that are stationed at the berth for onward movement out of the port. Figure 3 shows this method of delivery to be preferred during time of this study.

It showed that level of demand for storage facilities is very low.

This mean that sheds, warehouses and stacking areas are not put to adequate use and so revenue generation from these infrastructures are very low. On the average, less than $24 \%$ of annual cargo traffic passed through the storage facilities.

The effect of port users' choice of direct delivery was the flooding of the port with road vehicles and the accompanying congestion at the exit and entry points of the vehicles into and out of the port. The congestion in turn leads to longer berth idle times and longer turnaround time.

Table 2 show the infrastructural usage of transport network between the port and the hinterland. There it 
Table 1. Times at LPC.

\begin{tabular}{|c|c|c|c|c|c|c|c|}
\hline \multirow{2}{*}{ Year } & \multirow{2}{*}{ Tonnage handled (a) } & \multicolumn{2}{|c|}{ Ship working times } & \multicolumn{3}{|c|}{ Ship times } & \multirow{2}{*}{ Ratio of idle times/berth time } \\
\hline & & Working (h) & Idle at berth (h) & At berth (h) & In port (h) & In queue before berthing (h) & \\
\hline 1990 & 4605667 & 1013 & 2354 & 3367 & 3647 & 280 & 0.6991387 \\
\hline 1991 & 5748630 & 1027 & 2374 & 3401 & 3704 & 303 & 0.69802999 \\
\hline 1992 & 7076276 & 1708 & 3428 & 5136 & 5745 & 609 & 0.66744548 \\
\hline 1993 & 6593577 & 1464 & 3878 & 5342 & 6853 & 1511 & 0.72594534 \\
\hline 1994 & 5096695 & 945 & 2027 & 2972 & 3462 & 490 & 0.6820323 \\
\hline 1995 & 4885188 & 678 & 1791 & 2469 & 2705 & 236 & 0.7253949 \\
\hline 1996 & 4745190 & 702 & 1251 & 1953 & 2137 & 184 & 0.640553 \\
\hline 1997 & 4748566 & 1030 & 1533 & 2563 & 2818 & 255 & 0.59812719 \\
\hline 1998 & 6456064 & 964 & 1730 & 2694 & 2798 & 104 & 0.64216778 \\
\hline 1999 & 7144130 & 1835 & 2121 & 3956 & 4139 & 183 & 0.53614762 \\
\hline 2000 & 9164477 & 1987 & 1950 & 3937 & 4198 & 261 & 0.49530099 \\
\hline 2001 & 9234533 & 2013 & 2523 & 4536 & 4558 & 22 & 0.55621693 \\
\hline 2002 & 8474654 & 2001 & 2562 & 4563 & 4674 & 111 & 0.56147272 \\
\hline 2003 & 9489580 & 1927 & 1945 & 3872 & 4362 & 490 & 0.50232438 \\
\hline 2004 & 10959146 & 2192 & 1790 & 3982 & 4632 & 650 & 0.44952285 \\
\hline 2005 & 11710975 & 2190 & 1812 & 4002 & 4127 & 125 & 0.45277361 \\
\hline 2006 & 11283282 & 2111 & 2107 & 4218 & 4222 & 4 & 0.49952584 \\
\hline 2007 & 11028373 & 2182 & 2556 & 4738 & 4740 & 2 & 0.53946813 \\
\hline
\end{tabular}

Source: Lagos Port Complex, Annual Quay Records.

can be seen that road carries more traffic than other modes of transport when we consider nonliquid traffic.

The LPC is known to always have high berth occupancy. This is good but the results have shown that majority of the time, berths are occupied; the vessels at the berths are not being served but are rather idle (Table 1). In Table 1 it can be seen that idle time make up the bulk of the total time a ship spent at the port with an average of 0.592866 .

\section{Conclusion}

From the study, the use of direct cargo discharge from the vessels by virtually all the port users led to high vehicular traffic at the exit points which in turn resulted in longer berth idle time and time spent in port, poor capacity utilisation of storage facilities and other port infrastructure. High berth occupancy was recorded but this was quite deceptive as the over $30 \%$ of time spent in berths were idle berth times. Nigerian ports are known to have frequent congestion problems but from the study it was obvious that ship traffic to the port is low and berth capacity utilisation is about $50 \%$. This could only mean that the port's cargo handling procedure and discharge method is somewhat inadequate, resulting in non-utilisation of existing storage facilities, general poor port performance and the unwarranted congestion.

\section{RECOMMENDATIONS}

1. To solve this problem, better integration of the transport modes with each other at the land end should be encouraged. The rail and in-land transport systems must be efficient.

2. Cargo storage should be encouraged at the port and direct cargo discharge should be discouraged. Means of encouragement should be devised. Should direct cargo discharge method still be favoured by port users, efforts must then be made to divert traffic off the road mode to other 
Table 2. Use of infrastructures.

\begin{tabular}{|c|c|c|c|c|c|c|c|c|}
\hline \multirow[t]{2}{*}{ Year } & \multicolumn{4}{|c|}{ Tonnage(demand) } & \multicolumn{4}{|c|}{ Percentage change in demand for } \\
\hline & Rail & Road & Pipeline & Conveyor belt/suction pump & Rail & Road & Pipeline & Conveyor belt/suction pump \\
\hline 1990 & 128300 & 815912 & 3138164 & 455457 & - & - & - & - \\
\hline 1991 & 95600 & 1259320 & 3652002 & 101708 & -25 & 54 & 16 & -78 \\
\hline 1992 & - & 2043127 & 3981504 & 105145 & -100 & 62 & 9 & 934 \\
\hline 1993 & 63133 & 1011364 & 4049728 & 1469352 & 100 & -51 & 2 & 40 \\
\hline 1994 & - & 1303468 & 3819479 & 473753 & -100 & 29 & -18 & -68 \\
\hline 1995 & 64566 & 771346 & 3306711 & 718581 & 100 & -41 & 0 & 52 \\
\hline 1996 & & 506336 & 3369254 & 869600 & -100 & -34 & 2 & 21 \\
\hline 1997 & 8550 & 759219 & 2648380 & 1332417 & 100 & 50 & -21 & 53 \\
\hline 1998 & 6259 & 713674 & 3496614 & 2239517 & -27 & -6 & 32 & 68 \\
\hline 1999 & 5088 & 1003266 & 938780 & 4102581 & -19 & 41 & -73 & 83 \\
\hline 2000 & 5752 & 874737 & 992973 & 4538892 & 13 & -13 & 6 & 11 \\
\hline 2001 & 4643 & 789322 & 788922 & 6534228 & -19 & -10 & -21 & 44 \\
\hline 2002 & 3453 & 978763 & 1828222 & 5536767 & -26 & 24 & 132 & -15 \\
\hline 2003 & 5645 & 1092822 & 1928872 & 7456454 & 63 & 12 & 6 & 35 \\
\hline 2004 & 6456 & 1824533 & 1982776 & 7465433 & 14 & 67 & 3 & 0 \\
\hline 2005 & 6454 & 782752 & 2029938 & 7466389 & 0 & -57 & 2 & 0 \\
\hline 2006 & 7584 & 653622 & 2900188 & 8373735 & 18 & -16 & 43 & 12 \\
\hline 2007 & 8475 & 1028822 & 2987464 & 3454873 & 12 & 57 & 3 & -59 \\
\hline Average & 6214.45455 & 1011800.28 & 2657776.17 & 3483049 & 0 & 10 & 7 & 67 \\
\hline
\end{tabular}

Source: Lagos Port Complex Annual Quay Records

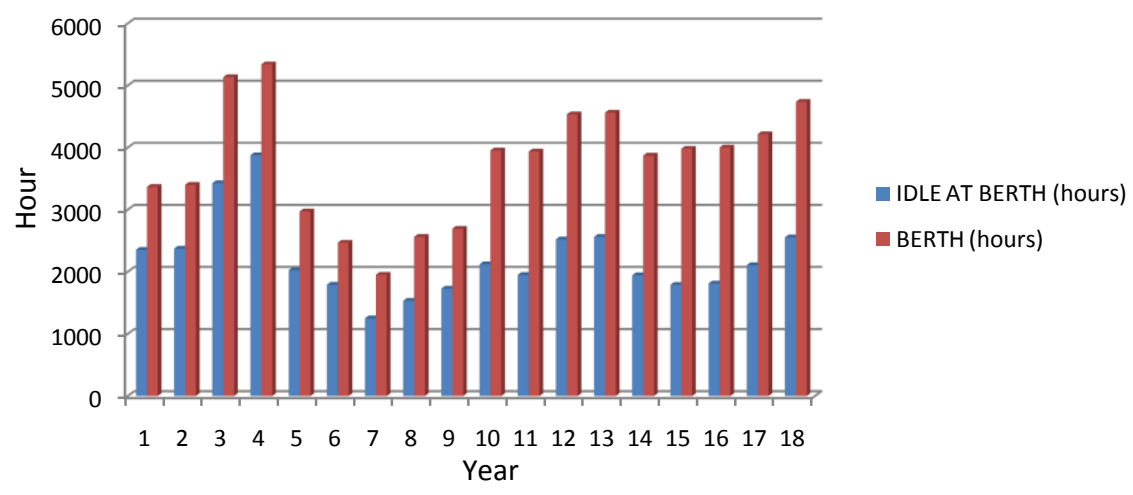

Figure 3. Idle time and worked times (Source: Field work). 
modes: rail and inland waterways. Companies that have access to railway tracks in their factories should be mandated to use the rail mode for moving their consignments out of the port.

\section{REFERENCES}

Bird J (1970). Seaports \& Terminals. Department of Transport Geography, University of Southampton, England. pp. 284-302.

Briggs M (1989). "Developing a Major Port Facility". Dev. World Transp., 1: $265-267$.

Emeghara AC (1992). "Capacity Utilization of Nigerian Ports'. An unpublished M.Sc. thesis submitted to Federal University of Technology, Owerri.

Hay A (1978). Linear Programming: elementary geographical applications of the transportation problem. (AMOG No. 11, Sheffield: Sheffield University).

ICC (1992). UNCTAD/ICC Rules for Multimodal Transport Documents. ICC publication Paris, p. 481.

ICC (1993). Uniform Customs and Practice for Documentary Credits. ICC Publication Paris, p. 500.
Laing FT and Hecker (1989). "A note on optimal waiting-a-service time ratios in large Ports.' Maritime Polit. Manage. Rev., 16(1): 85-86

Levinson MD (1988). "On the Tolls Falls: A Model Network Financing.' A Ph.D. thesis submitted to the University of California, Los Angeles. p. 6.

Okafor PN (1998). "Traffic Management of containers in Nigerian Seaports.' An unpublished thesis submitted to the Chartered Institute of Logistics and Transport in Nigeria, Official Records of the General Assembly, $32^{\text {nd }}$ session. Supplement No. 38 (A/32/38). pp. 14-16, 5859.

Pieter DL (1998). "Time centrality in Transport.' Delivered at the $8^{\text {th }}$ World Conference on Transport Research, Brussels. p. 1149.

Pyre CJ (1989). "Maritime Infrastructure - an Overview'. Dev. World Transp., 1: 260-264.

UNCTAD/SIDA (1983). Importing Port Performance: Management of General Cargo Operations Drake Educational Associates Ltd., Cardiff. Geneva: UNTAD, pp. 1-16.

Wolfhard A (1989). "Port Problems in Developing Countries'. Dev. World Transp., 1: 268-270. 